\title{
Effects of Process Parameters on Ozone Washing for Denim using $3^{3}$ Factorial Design
}

\author{
FAREHA ASIM*, AND MUZZAFFAR MAHMOOD** \\ RECEIVED ON 30.08.2016 ACCEPTED ON 22.11.2016
}

\begin{abstract}
Denim garment is getting popular day by day. It is highly demandable because of its versatility, comfort and durability. Different techniques of denim washing increase this demand drastically. Denim washing is the process to enhance the appearance of a garment. This enhanced appearance may be the aged look, faded look, greyer cast, or any other shade setting or resin application. The two most advanced washing techniques are; ozone wash and laser wash. The effects of ozone on environment as well as on the garment are significant and cannot be neglected because number of benefits achieved such as time saving, less energy consumption, chemical, labour cost reduction, less discharge of water and chemicals. Therefore, effects of process parameters on ozone washing for denim fabric have been investigated in this research work using three level factorial design. $3^{3}$ factorial design has been designed and conducted to investigate the effect of gas concentration, time and speed on the response variables namely; Shrinkage, Tensile and Tear strength of ozone washing. The influence of individual factors and their interactions has been critically examined using software Design Expert 8.0. Prior to the analysis of variance model accuracy has been examined through various residuals plots. The study of residuals plots shown that the residuals are normally distributed and significant evidence of possible outliers was not found. So the model can be used to predicted results with $95 \%$ confidence interval. The results from the experiment suggest that two out of three factors were significant, which are speed and time that influences mainly on the tear strength of the denim garment.
\end{abstract}

Key Words: Factorial Design, Ozone Washing, Shrinkage, Tensile Strength, Tear Strength.

\section{INTRODUCTION}

$\mathrm{D}$ enim garment is getting popular day by day and becomes highly demandable because of its versatility, comfort and durability [1]. Different techniques of denim washing increase this demand drastically. Washing is the process to enhance the appearance of a denim garment; it is the value added process which improves the chemical, mechanical as well as the aesthetical properties of denim garment [2-4]. Ozone Washing for denim garment is an advanced waterless technology which is not being utilized at production level in industry due to lack of awareness The influence of washing on the properties of the denim garment had been

Corresponding Author (E-Mail: fareha@neduet.edu.pk)

* Department of Textile Engineering, NED University of Engineering \& Technology, Karachi.

** Department of Mechatronics Engineering, PAF Karachi Institute of Economics \& Technology, Karachi.

Mehran University Research Journal of Engineering \& Technology, Volume 36, No. 4, October, 2017 [p-ISSN: 0254-7821, e-ISSN: 2413-7219] 
investigated earlier [5-8]. Technology of industrial denim washing including stone wash, micro sanding, denim bleaching, enzyme wash and acid wash had been reviewed by some researchers [9]. Sustainable and ecological finishing technology for Denim including laser finishing and ozone fading had been studied [10]. The authors discussed that the integration of such technologies into the conventional washing lines will ensure that vintage looks and other fashion effects can be created on jeans with much less water. In such cases, the effluent output is reduced to a negligible quantity, thus transforming denim washing to an environmentally friendly process. Some parameters affecting dry and wet ozone bleaching of Denim fabric had been investigated earlier [11]. However, most prior studies did not experimentally evaluate the effect of ozone gas concentration, speed and time on mechanical properties of denim fabric. Furthermore, DOE (Design of Experiment) is a statistical technique used to identify key factors and levels that influence system performance and variability. This technique is especially useful when there is need to understand the interactions and effects of system variables in an absence of concrete information [12]. This research work scrutinizes the effects of process parameter of ozone washing on the properties of denim garment using factorial design. After an extensive literature review, key factors namely gas concentration, speed and time had been identified which are statistically examined through $3^{3}$ factorial design. Ozone effect on mechanical properties of the denim was studied through the measurement of ultimate tensile strength, tear strength and shrinkage respectively.

\section{EXPERIMENTAL}

\subsection{Fabric}

The composition of fabric under consideration is $70 \%$ cotton, 28\% PET and 2\% Lycra. The quality of the fabric is 3/1 twill weighs $9.50 \mathrm{Oz}$. The fabric was dyed with indigo dye and used without any prior distortion.

\section{$2.2 \quad$ Method}

The ozone washing process is carried out as follows; in the first stage denim fabric sample was rinsed with tap water and squeezed with hydro extractor. In the second stage the sample is placed in the ozone washing machine and the process parameters namely gas concentration, speed and time have been set according to the $3^{3}$ experimental design arrangement as stated in

Tables 1-2.

\subsection{Experiment Design}

$3^{3}$ factorial design was used to investigate the effect of different factors namely: (i) gas concentration, (ii) speed and (iii) time on ozone washing of denim garment. $\mathrm{A} 3^{3}$ factorial design of 27 was run according to the design matrix shown in Table 1. The experiments were performed in random order. The results were analyzed using software Design Expert 8.0. The responses investigated were the shrinkage, tensile and tear strength in both warp and weft directions. The details of the experimental design arrangement are shown in Tables 1-2.

TABLE 1. POTENTIAL DESIGN FACTORS AND RESPECTIVE LEVELS USED IN IN $3^{3}$ FACTORIAL DESIGN

\begin{tabular}{|c|c|c|c|c|}
\hline \multicolumn{2}{|c|}{ Factor Name } & \multicolumn{3}{c|}{ Levels } \\
\cline { 3 - 5 } & Gas Concentration & $30 \%$ & 0 & +1 \\
\hline A & Speed & $10 \mathrm{rpm}$ & $60 \%$ & $90 \%$ \\
\hline Gas Concentration & Time & $10 \mathrm{~min}$ & $15 \mathrm{rpm}$ & $20 \mathrm{rpm}$ \\
\hline B & & $30 \mathrm{~min}$ & $40 \mathrm{~min}$ \\
\hline
\end{tabular}

Mehran University Research Journal of Engineering \& Technology, Volume 36, No. 4, October, 2017 [p-ISSN: 0254-7821, e-ISSN: 2413-7219] 


\subsection{Evaluation of Fabric Properties}

The samples processed were conditioned (at temperature $25 \pm 1^{\circ} \mathrm{C}$ and relative humidity $65 \pm 1 \%$ ) before the evaluation of fabric properties. Tensile strength values were assessed by grab test method [13]. Tear strength values were evaluated used Elmendorf [14]. Shrinkage of the fabric is evaluated by standard test procedure [15].

TABLE 2. $3^{3}$ FACTORIAL DESIGN MATRIX

\begin{tabular}{|c|c|c|c|}
\hline Run & $\begin{array}{c}\text { Gas } \\
\text { Concentration } \\
\text { (wt/wt\%) }\end{array}$ & $\begin{array}{l}\text { Speed } \\
\text { (rpm) }\end{array}$ & $\begin{array}{l}\text { Time } \\
\text { (min) }\end{array}$ \\
\hline 1 & 60 & 10 & 30 \\
\hline 2 & 30 & 15 & 10 \\
\hline 3 & 30 & 10 & 30 \\
\hline 4 & 90 & 20 & 20 \\
\hline 5 & 90 & 10 & 10 \\
\hline 6 & 30 & 20 & 20 \\
\hline 7 & 90 & 15 & 10 \\
\hline 8 & 60 & 10 & 10 \\
\hline 9 & 60 & 20 & 10 \\
\hline 10 & 30 & 10 & 10 \\
\hline 11 & 30 & 20 & 30 \\
\hline 12 & 60 & 15 & 10 \\
\hline 13 & 90 & 20 & 30 \\
\hline 14 & 90 & 15 & 20 \\
\hline 15 & 60 & 15 & 20 \\
\hline 16 & 60 & 20 & 20 \\
\hline 17 & 60 & 20 & 30 \\
\hline 18 & 90 & 20 & 10 \\
\hline 19 & 30 & 10 & 20 \\
\hline 20 & 30 & 15 & 20 \\
\hline 21 & 60 & 10 & 20 \\
\hline 22 & 30 & 15 & 30 \\
\hline 23 & 90 & 15 & 30 \\
\hline 24 & 30 & 20 & 10 \\
\hline 25 & 90 & 10 & 30 \\
\hline 26 & 60 & 15 & 30 \\
\hline 27 & 90 & 10 & 20 \\
\hline
\end{tabular}

\section{RESULTS AND DISCUSSION}

After processing the experimental trials, shrinkage, tensile and tear strength values were measured. The results obtained from the different experimental trials are presented in Table 3. All the response variables were statistically analyzed using software Design Expert. The ANOVA (Analysis of Variance) is shown in Table 4. The results from the experiment suggest that two of the three factors namely speed and time were significant for the Tear strength.

TABLE 3. EXPERIMENTAL RESULTS OF $3^{3}$ FACTORIAL DESIGN

\begin{tabular}{|c|c|c|c|c|c|c|}
\hline \multirow[t]{2}{*}{ Run } & \multicolumn{2}{|c|}{ Shrinkage (\%) } & \multicolumn{2}{|c|}{$\begin{array}{l}\text { Tensile Strength } \\
(\mathrm{kgf} / \mathrm{m} 2)\end{array}$} & \multicolumn{2}{|c|}{$\begin{array}{l}\text { Tear Strength } \\
\text { (kgf/m2) }\end{array}$} \\
\hline & Warp & Weft & Warp & Weft & Warp & Weft \\
\hline 1 & -0.4 & -0.4 & 72.0 & 64.0 & 8.064 & 7.68 \\
\hline 2 & -0.8 & -0.8 & 73.1 & 70.1 & 9.6 & 9.152 \\
\hline 3 & -1 & -1.0 & 69.1 & 63.0 & 7.424 & 9.088 \\
\hline 4 & -0.4 & -0.4 & 73.0 & 63.4 & 7.424 & 7.808 \\
\hline 5 & 0.2 & 0.2 & 74.6 & 71.0 & 9.024 & 9.088 \\
\hline 6 & -1.0 & -1.0 & 71.4 & 69.5 & 7.808 & 8.832 \\
\hline 7 & -1.0 & -1.0 & 69.5 & 69.6 & 9.6 & 9.984 \\
\hline 8 & -1.0 & -1.0 & 73.8 & 74.0 & 9.088 & 8.96 \\
\hline 9 & -1.4 & -1.4 & 73.1 & 72.1 & 8.704 & 9.6 \\
\hline 10 & -0.4 & -0.4 & 78.1 & 65.9 & 8.448 & 8.32 \\
\hline 11 & -1.0 & -1.0 & 72.3 & 65.2 & 7.296 & 8.448 \\
\hline 12 & 0.6 & 0.6 & 79.4 & 64.1 & 8.704 & 9.984 \\
\hline 13 & -1.0 & -1.0 & 72.5 & 65.0 & 7.808 & 9.088 \\
\hline 14 & 0.4 & 0.4 & 78.4 & 66.2 & 8.064 & 8.832 \\
\hline 15 & 0.2 & 0.2 & 77.2 & 70.6 & 8.96 & 8.512 \\
\hline 16 & -1.0 & -1.0 & 73.9 & 71.1 & 8.064 & 9.6 \\
\hline 17 & -2.0 & -2.0 & 71.2 & 66.2 & 7.552 & 8.832 \\
\hline 18 & -0.4 & -0.4 & 74.0 & 71.6 & 8.32 & 8.832 \\
\hline 19 & 0.4 & 0.4 & 73.8 & 67.1 & 9.6 & 8.0 \\
\hline 20 & -1.4 & -1.4 & 71.4 & 75.0 & 7.808 & 8.064 \\
\hline 21 & -0.6 & -0.6 & 68.1 & 67.5 & 8.064 & 8.576 \\
\hline 22 & 0.0 & 0.0 & 73.0 & 62.2 & 7.936 & 7.04 \\
\hline 23 & -1.0 & -1.0 & 73.9 & 71.1 & 8.064 & 9.6 \\
\hline 24 & -1.0 & -1.0 & 76.2 & 75.3 & 8.448 & 9.728 \\
\hline 25 & 0.2 & 0.2 & 69.1 & 64.8 & 7.296 & 7.424 \\
\hline 26 & 0.0 & 0.0 & 69.4 & 65.2 & 8.192 & 8.192 \\
\hline 27 & -0.6 & -0.6 & 70.0 & 74.2 & 7.936 & 8.576 \\
\hline
\end{tabular}


Table 4 shows the ANOVA results of ozone washing for denim garment. The model p-value of 0.0012 implied that the respective model is significant for ozone washing. As can be seen in Table 4, the p-value of factor B-speed and C-Time is lower than 0.05 therefore, both B-speed and Ctime are significant model terms for ozone washing of denim garment.

The main factor plots of speed and time areshown in Figs. 1-2. Fig. 1 showed that Tear strength increases as the speed increases till level of 15rpm and start decreasing as the speed goes above this value. Fig. 2 depict that the Tear strength decreases as the time increases from 10 min. As more contact of fabric to the machine along with ozone gas, abrade the surface of the denim due to which strength decreases. After the statistical analysis, it is evident that speed and time are the main potential parameters of the ozone washing that influences mainly on the tear strength of the garment.

Influence of Gas Concentration: Ozone gas concentration is not playing a significant role on any of the mechanical property of denim fabric. This is because, when we increase the concentration of the ozone gas, the speed of the machine will increase and the treatment time will reduce respectively. So there is no noticeable effect on tear strength of the denim fabric. However, tear strength will certainly reduce, if gas concentration will increase keeping speed and time constant.

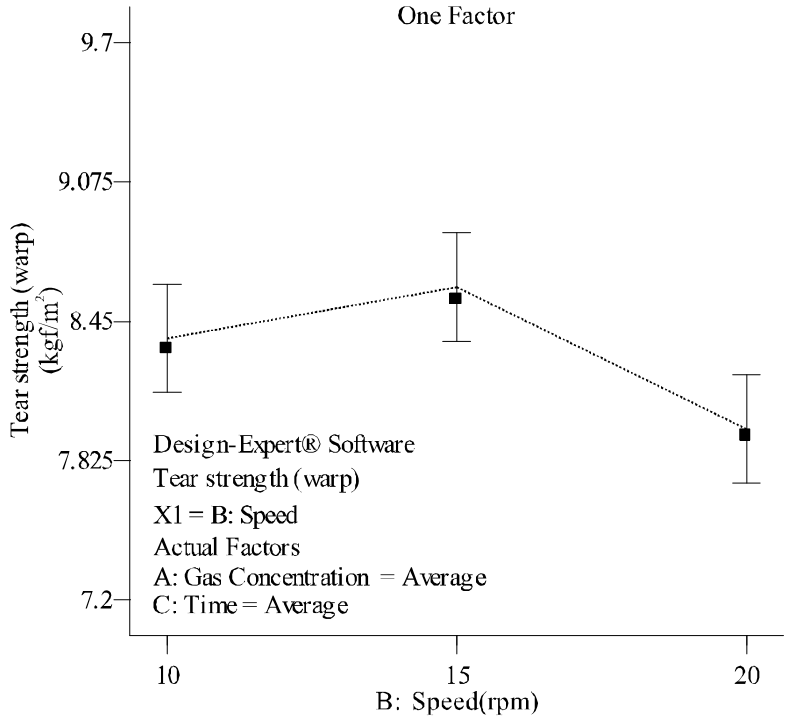

FIG. 1. EFFECT OF SPEED ON TEAR STRENGTH

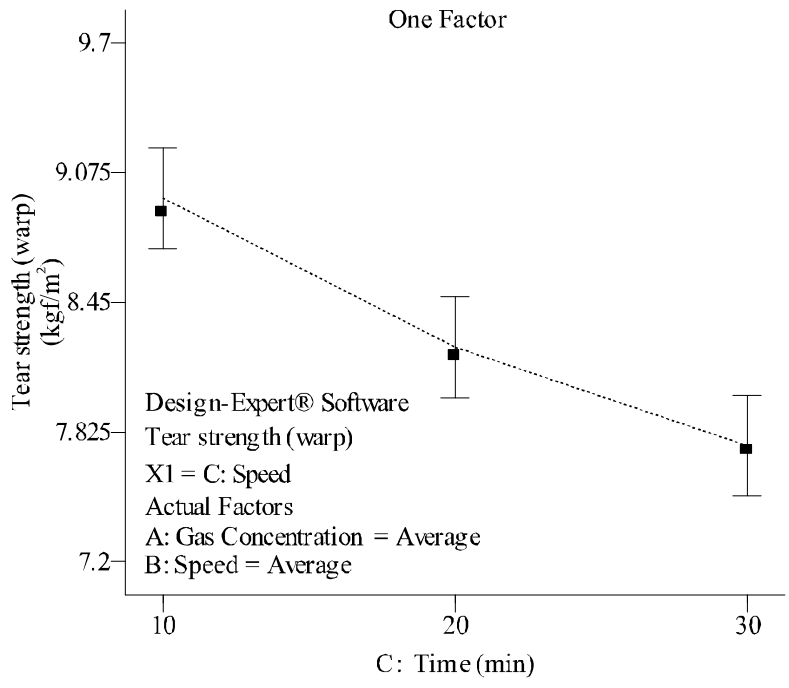

FIG. 2. EFFECT OF TIME ON TEAR STRENGTH

TABLE 4. ANOVA FOR SIGNIFICANT RESPONSE

\begin{tabular}{|c|c|c|c|c|c|}
\hline Source & Sum of Squares & $\mathrm{df}$ & Mean Square & F -Value & p-Value \\
\hline Model & 7.90 & 6 & 1.32 & 5.87 & 0.0012 \\
\hline A-Gas Concentration & 0.19 & 2 & 0.096 & 0.43 & 0.6578 \\
\hline B-Speed & 1.73 & 2 & 2.99 & 13.32 & 0.0386 \\
\hline C-Time & 5.98 & 20 & 0.22 & & 0.9376 \\
\hline Residual & 4.49 & 26 & & & 0.9001 \\
\hline Cor Total & 12.39 & & R2 & \\
\hline Std. Dev. & \multicolumn{2}{|c|}{0.47} & Adj R2 & \\
\hline Mean & 8.27 &
\end{tabular}

Mehran University Research Journal of Engineering \& Technology, Volume 36, No. 4, October, 2017 [p-ISSN: 0254-7821, e-ISSN: 2413-7219] 
Influence of Speed: Tear strength increases as the speed increases at level of 15rpm and start decreasing as the speed goes above this value this is because at the start ozone strengths the material but as it goes on with high speed the tear strength get reduced.

Influence of Time: Tear strength decreases as the time increases. Because the more contact of fabric to the machine along with gas, abrade the surface of the denim, consequently strength decreases.

\section{CONCLUSION}

The statistical analysis of significant factors namely gas concentration, speed and time including ANOVA has been conducted for ozone washing of denim fabric. During this experimental study, following levels of process parameters for ozone washing are recommended that will help to improve the quality of denim fabric as well as the economy of industry. As the gas concentration does not have significant effect on any of the considered responses, so it should be taken at the minimum level of $30 \%$. This will reduce the consumption of gas that will ultimately increase the economy. Keeping rest of things constant, speed and time are the main potential parameters of ozone washing that influences mainly on the tear strength of the garment. Speed and time should be maintained at $15 \mathrm{rpm}$ for $10 \mathrm{~min}$, if high tear strength of denim fabric is required. The remaining mechanical properties i.e. tensile strength (warp \& weft) and shrinkage (warp \& weft) do not have significant effect as undertaking the three parameters i.e. Gas Concentration, Time and Speed.

\section{FUTURE WORK}

The optimization of the process parameters on tear strength is recommended by the authors for the extension of this work. Furthermore, as the effect of mechanical properties of denim garment on exposure to ozone gas was successfully analyzed, future work may comprises of analysis of chemical properties of the garment such as colour fastness to washing, crocking and laundering.

\section{ACKNOWLEDGEMENT}

The authors wish to express their gratitude to NED University of Engineering \& Technology, Karachi, for providing research opportunity and logistics while many thanks to Artistic Milliner Pvt. Limited, Karachi, Pakistan, for carrying out the necessary experimental work.

\section{REFERENCES}

[1] Behling, D., "Fashion Change and Demographics: A Model”, Clothing and Textiles Research Journal, Volume 4, No. 1, pp. 18-24, 1985.

[2] Gusakov, A.V., Sinitsyn, A.P., Berlin, A.G., Markov, A.V., and Ankudimova, N.V., "Surface Hydrophobic Amino Acid Residues in Cellulase Molecules as a Structural Factor Responsible for their High Denim-Washing Performance”, Enzyme and Microbial Technology, Volume 27, No. 9, pp. 664-671, 2000.

[3] Card, A., Moore, M.A., and Ankeny, M., "Garment Washed Jeans: Impact of Launderings on Physical Properties”, International Journal of Clothing Science and Technology, Volume 18, No. 1, pp. 43-52, 2006.

[4] Artur, C., Jose, M., Luis, A., and Douglas, K., "Indigo Backstaining During Cellulase Washing”, Textile Research Journal, Volume 68, No. 6, pp. 398-401, 1998.

[5] Kan, C.W., and Wong, W.Y., "Color Properties of Cellulase-Treated Cotton Denim Fabric Manufactured by Torque-Free Ring Spun Yarn”, Textile Research Journal, Volume 81, No. 9, pp. 875-882, 2011.

[6] Cheung, H.F., Kan, C.W., Yuen, C.W.M, Yip, J., and Law, M.C., "Colour Fading of Textile Fabric by Plasma Treatment”, Journal of Textiles, pp. 1-4, 2013.

[7] Kan, C.W., and Yuen, C.W.M., "Evaluation of the Performance of Stretch Denim Fabric under the Effect of Repeated Home Laundering Processes”, International Journal of Fashion Design, Technology and Education, Volume 2, No. 3, pp. 71-79,2009. 
[8] Mahmood, G., Bahareh, M., Sheila, S., Abbas, A., and Abosaeed, R., "Decolorization of Denim Fabrics with Cold Plasmas in the Presence of Magnetic Fields”, Plasma Processes and Polymers, Volume 3, No. 3, pp. 316-321, 2006.

[9] Arjun, D., Hiranmayee, J. , and Farheen, M.N., “Technology of Industrial Denim Washing”, International Journal of Industrial Engineering \& Technology, Volume 3, No. 4, pp. 25-34, 2013.

[10] Khalil, E., "Sustainable and Ecological Finishing Technology for Denim Jeans”, AASCIT Communications, Volume 2, No. 5, pp. 159-163, 2015.

[11] Hmida, S., and Ladharic, N., "Study of Parameters Affecting Dry and Wet Ozone Bleaching of Denim Fabric”, Ozone: Science \& Engineering, Volume 38, No. 3, pp. 175-180, 2016.
[12] Montgomery, D. C., "Design and Analysis of Experiments”, John Wiley \& Sons, 5 $5^{\text {th }}$ Edition, 2001.

"Standard Test Method for Grab Breaking Load and Elongation of Geotextiles”, Active Standard ASTM D4632/D4632M|Developed by Subcommittee: D35.01, Book of Standards, Volume 4, No. 13, 2015.

"Standard Test Method for Tearing Strength of Fabrics by Falling-Pendulum (Elmendorf-Type) Apparatus”, Active Standard ASTM D1424|Developed by Subcommittee: D13.60, Book of Standards, Volume 7, No. 1, 2013.

[15] "Dimensional Changes of Fabric after Home LaunderingAATCC Test Method 135-2004”, AATCC Technical Manual, pp. 225-228, 2009. 